\title{
Preparation of modified magnesium hydroxide and its application in PA66
}

\author{
CHEN Hong ${ }^{1}$, ZHU Bao-wei ${ }^{1}$, LIU Haiyan ${ }^{1}$, YANG He${ }^{2}$, JIANG Li-peng ${ }^{2}$ \\ ${ }^{1}$ Chemical and environmental Engineering Department, Yingkou Institute of Technology, Yingkou, 115014, China \\ ${ }^{2}$ Liaoning Yinzhu Chemtex Group co., LTD, Yingkou, 115000, China
}

\begin{abstract}
In the present study, the modified magnesium hydroxide was prepared by precipitation method using $\mathrm{Mg}\left(\mathrm{NO}_{3}\right), \mathrm{NaOH}$, and silane coupling 702 modifier as raw materials. The optimal reaction conditions were obtained as follows: sodium hydroxide was added to magnesium nitrate solution by dropping, the dropping speed of sodium hydroxide was $2 \mathrm{ml} / \mathrm{min}$, the reaction temperature was $60^{\circ} \mathrm{C}$, and the ratio of modifier dosage to total solution volume was $7 / 100(\mathrm{~g} / \mathrm{ml})$. The oil absorption value and XRD were used to characterize the modified $\mathrm{Mg}(\mathrm{OH})_{2}$. In the application, the modified magnesium hydroxide was mixed with pentaerythritol octahydrogen tetraphosphate(PEPA) and applied to nylon 66(PA66). The flame retardancy and mechanical properties of the nylon 66(PA66)composite were studied.
\end{abstract}

\section{Introduction}

Flame retardant is an important part of daily life, it can be added into the material to improve the flame retardant performance of the material and plays a key role in preventing the occurrence and spread of fire. There is self-extinguishing, heat resistance and fire resistance after the flame retardant has been added. Flame retardants are being used in more and more fields such as construction, textiles, transportation, aerospace, electronics, plastic materials, etc.[1]. Magnesium hydroxide is an added inorganic flame retardant, and there is good environmental protection properties in raw material source, preparation process and waste disposal comparing with the same type of inorganic flame retardant. However, modification treatment is often required due to its poor compatibility with the polymer. Generally, saturated or unsaturated higher fatty acid salts, anionic surfactants and silicone coupling agents can be used for surface modification of magnesium hydroxide particles[2-8]. Modified magnesium hydroxide can effectively improve the compatibility with polymers .

The advantages of PA66 is high strength, good wear resistance and fine handle, and is widely used in industrial and military fields. PA66 is limited in its application due to its poor flame retardancy. The purpose of this experiment is to enhance the flame retardancy of PA66 and expand its application range by mixing modified magnesium hydroxide with PEPA in PA66.

\section{Experiments}

\subsection{Materials and apparatus}

Sodium hydroxide, magnesium nitrate, DOP, silane coupling agent 702 $\left(\mathrm{NH}_{2}-\mathrm{CH}_{2}-\mathrm{CH}_{2}-\mathrm{NH}-\mathrm{CH}_{2}-\mathrm{CH}_{2}-\right.$ $\left.\mathrm{NHC}_{3} \mathrm{H}_{6} \mathrm{CH}_{3} \mathrm{Si}\left(\mathrm{OCH}_{3}\right)_{2}\right)$, pentaerythritol octahydrogen tetraphosphate (PEPA) are all analytical purity, Shenyang Xinhua Reagent Factory.Nylon 66 (PA66)Liaoning Yinzhu Chemtex Group co., LTD

SHB-B95 circulating water multi-purpose vacuum pump, Bruker D8 ADVANCE X-ray diffractometer, $\mathrm{Cu}$ target $\mathrm{K} \alpha$-ray $(\lambda=0.15406 \mathrm{~nm}$, tube pressure $40 \mathrm{kV}$, tube flow $30 \mathrm{~mA}$, scanning range $(10 \sim 90)^{\circ}$; AK36 twin screw extruder, CJ50E II precision injection molding machine, HC-2 oxygen index tester and CZF-5 horizontal vertical combustion tester.

\subsection{Experimental methods}

\subsubsection{Preparation of modified magnesium hydroxide}

In the experiment, the sodium hydroxide solution reacts with the magnesium nitrate solution by a precipitation method, and the reaction is as follows:

$\mathrm{Mg}\left(\mathrm{NO}_{3}\right)_{2}+2 \mathrm{NaOH}=\mathrm{Mg}(\mathrm{OH})_{2} \downarrow+2 \mathrm{NaNO}_{3}$

$100 \mathrm{~mL} 2 \mathrm{~mol} / \mathrm{L}$ magnesium nitrate solution and a certain amount of modifier accurately are added into the beaker. $2 \mathrm{~mol} / \mathrm{L} 200 \mathrm{~mL}$ magnesium hydroxide solution is added the constant pressure titration funnel and slowly is dropped into the magnesium nitrate solution at $60^{\circ} \mathrm{C}$, and a certain amount of magnesium nitrate solution dropping speed is controlled. When the

\footnotetext{
* Corresponding author: chh021567@126.com
} 
solution is fully reacted and the temperature is kept unchanged, the solution is settled for about $50 \mathrm{~min}$. The solution is subjected to suction filtration after complete reaction. At the end of suction filtration, a proper amount of absolute ethanol is added to the buchner funnel, the filter cake is washed. The product is further subjected to suction filtration. After the end of filtration, the filter cake was dried to obtain modified magnesium hydroxide. Modified magnesium hydroxide was reserved for use.

\subsubsection{Determination of oil absorption value}

Oil absorption value expressed as volume $\mathrm{X}(\mathrm{mL})$ of $1 \mathrm{~g}$ of magnesium hydroxide absorbed DOP, calculation method: $\mathrm{X}=\mathrm{V} / \mathrm{m}$. Where $\mathrm{V}$ is the volume of DOP consumed, $\mathrm{mL} ; \mathrm{m}$ is the mass of the sample, $\mathrm{g}$.

\subsubsection{Preparation of flame retardant PA66}

The samples were weighed according to the proportion of modified magnesium hydroxide, PEPA and PA66. The mixture was uniform mixed and dried in vacuum at $80^{\circ} \mathrm{C}$ for $12 \mathrm{~h}$. After drying, it was extruded and granulated on a twin-screw extruder. Mixed material was molded into a standard sample.

\subsubsection{Performance measurement}

Oxygen index is tested according to GB/T240693. Vertical combustion is tested according to GB460984. The extrusion temperature of $\mathrm{AK} 36$ twin screw extruder is set as follows: $250^{\circ} \mathrm{C}-270^{\circ} \mathrm{C}$, and the screw speed is $60 \mathrm{r} / \mathrm{min}$. The temperature of injection molding spline was $270^{\circ} \mathrm{C}$, and the spline was tested after being placed for 24 hours.

\section{Results and discussion}

\subsection{Optimization of preparation conditions of modified magnesium hydroxide}

The modification effect of magnesium hydroxide was evaluated by analyzing the oil absorption value. The oil absorption value is related to the intergranular space, surface performance, specific surface area and other factors, which can characterize the modification results of magnesium hydroxide. With small intergranular space, high dispersion and small surface polarity, the ineffective DOP absorption of powder will be reduced and the oil absorption value is small.The above effect shows that the modification effect is remarkable. The modification effect is poor if the oil absorption value is large.

On the basis of single factor experiment, the reaction temperature, sodium hydroxide drop acceleration and the amount of modifier were selected as factors. The preparation conditions of modified magnesium hydroxide were optimized by orthogonal experiment with three factors and three levels. The factors are shown in table 1 and the experimental results are shown in table 2.

Table 1. Orthogonal empirical factors table

\begin{tabular}{llll}
\hline Factors & $\begin{array}{l}\text { Amount of } \\
\text { modifier } \\
(\mathbf{g} / \mathbf{m l})\end{array}$ & $\begin{array}{l}\text { Drop } \\
\text { acceleration } \\
(\mathbf{m l} / \mathbf{m i n}) \\
\mathbf{B}\end{array}$ & $\begin{array}{l}\text { Reaction } \\
\text { temperature } \\
\left({ }^{\circ} \mathbf{C}\right)\end{array}$ \\
\hline 1 & 1 & 1 & \\
\hline
\end{tabular}

Table 2 Orthogonal empirical results and analysis

\begin{tabular}{lllll}
\hline No. & $\begin{array}{c}\text { Factor } \\
\mathbf{A}\end{array}$ & $\begin{array}{c}\text { Factor } \\
\mathbf{B}\end{array}$ & $\begin{array}{c}\text { Factor } \\
\mathbf{C}\end{array}$ & $\begin{array}{l}\text { Oil } \\
\text { absorption } \\
\text { value (g / } \\
\text { ml) }\end{array}$ \\
\hline 1 & 1 & 1 & 1 & 0.167 \\
2 & 1 & 2 & 2 & 0.158 \\
3 & 1 & 3 & 3 & 0.147 \\
4 & 2 & 1 & 2 & 0.156 \\
5 & 2 & 2 & 3 & 0.155 \\
6 & 2 & 3 & 1 & 0.146 \\
7 & 3 & 1 & 3 & 0.143 \\
8 & 3 & 2 & 1 & 0.146 \\
9 & 3 & 3 & 2 & 0.151 \\
$\mathrm{~K}_{1}$ & 0.472 & 0.466 & 0.459 & \\
$\mathrm{~K}_{2}$ & 0.457 & 0.459 & 0.465 & \\
$\mathrm{~K}_{3}$ & 0.440 & 0.444 & 0.445 & \\
$\mathrm{R}$ & 0.032 & 0.022 & 0.020 & \\
\hline & & & & \\
\hline
\end{tabular}

From the results of orthogonal experiment, it is found that there is a great influence of modifier amount on the experiment, and the second is the drop acceleration of sodium hydroxide, and the least is the reaction temperature. The better reaction condition is $\mathrm{A}_{3} \mathrm{~B}_{3} \mathrm{C}_{3}$. That is, the amount of modifier was $7 \mathrm{~g} / \mathrm{ml}$ (according to the added amount), the drop acceleration of sodium hydroxide was $2 \mathrm{ml} / \mathrm{min}$ and the reaction temperature was $60^{\circ} \mathrm{C}$. The comparison results between the optimum $\mathrm{A}_{3} \mathrm{~B}_{3} \mathrm{C}_{3}$ condition and the experiment No.7 in orthogonal table showed that the oil absorption value of experiment No.7 was $0.142 \mathrm{~g} / \mathrm{ml}$ and that of $\mathrm{A}_{3} \mathrm{~B}_{3} \mathrm{C}_{3}$ was $0.138 \mathrm{~g} / \mathrm{ml}$. Therefore, the optimum modification conditions were $7 \mathrm{~g} / \mathrm{ml}$ of silane coupling modifier (based on the total volume), $2 \mathrm{ml} / \mathrm{min}$ of sodium hydroxide, and $60^{\circ} \mathrm{C}$ of reaction temperature. 


\subsection{Characterization of modified magnesium hydroxide}

Fig. 1 is an X-ray diffraction (XRD) pattern of the modified magnesium hydroxide. As can be seen from Fig.1, the product is hexagonal magnesium hydroxide, which has a good consistency with JCPDS75-1527.

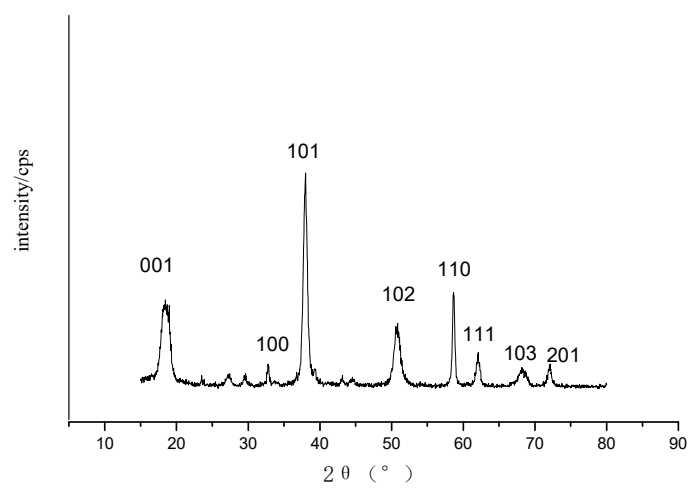

Fig. 1. X-ray diffraction (XRD) spectrum of modified magnesium hydroxide

\subsection{Flame retardant application of modified magnesium hydroxide}

\subsubsection{Combustion testing}

Modified magnesium hydroxide (MH) and PEPA with different ratios were added to PA66, and the effect of the compound additives on the flame retardancy of PA66 was investigated. The results are shown in table 3 .

Table 3. Flame retirement of PA66 at different proportions magnesite hydroxide and PEPA

\begin{tabular}{lllllll}
\hline No. & $\begin{array}{l}\text { MH } \\
(\mathrm{Phr})\end{array}$ & $\begin{array}{l}\text { PEPA } \\
(\mathrm{Phr})\end{array}$ & $\begin{array}{l}\text { PA66 } \\
(\mathrm{Phr})\end{array}$ & UL-94 & $\begin{array}{c}\text { LOI } \\
(\%)\end{array}$ & $\begin{array}{l}\text { Droplet } \\
\text { phenom } \\
\text { enon }\end{array}$ \\
\hline 1 & 0 & 0 & 100 & - & 23.5 & Yes \\
2 & 30 & 0 & 100 & $\mathrm{~V}-2$ & 28 & No \\
3 & 28 & 3 & 100 & $\mathrm{~V}-2$ & 29.5 & No \\
4 & 26 & 5 & 100 & $\mathrm{~V}-1$ & 30.5 & No \\
5 & 24 & 7 & 100 & $\mathrm{~V}-0$ & 32.5 & No \\
6 & 22 & 9 & 100 & $\mathrm{~V}-0$ & 33 & No \\
\hline
\end{tabular}

It can be seen from table 3 that pure PA66 thick spline UL94 is V-2 $(3.2 \mathrm{~mm})$ and droplets appear during combustion. LOI is only $23.5 \%$. The oxygen index (LOI) of PA66 material is $23.5 \%$ and the vertical combustion is V-2 grade.The flame retardancy is obviously enhanced when 30phr of modified magnesium hydroxide are used alone. It also can be seen from table 3 that the vertical combustion performance of PA66 can reach $32.5 \%$ of LOI with increasing PEPA content .The increase rate of LOI of PA66 was slow and the vertical combustion performance was invariable when the addition of PEPA reached 7phr. PA66 obtained good flame retardancy when the ratio of modified magnesium hydroxide to PEPA was 24:7(phr:phr) . Reasons for PA66 flame retardancy improvement may be due to the thermal oxygen decomposition of PA66 to form $\mathrm{H}_{2} \mathrm{O}, \mathrm{NH}_{3}$ and $\mathrm{CO}_{2}$, and these gases can all act as dilutions in the gas phase. Meanwhile,the PEPA absorbs heat due to temperature rising when PA66 burns, which is favorable for char formation. The addition of PEPA and MH can play a synergistic flame retardant effect in PA66.

\subsubsection{Mechanical properties of PA66 material added with flame retardant}

The mechanical properties of PA66 added with compound flame retardant were measured. The results are shown in table 4.

It can be seen from table 4 that the tensile strength of PA66 slightly decreased, while the elongation at break and notched impact strength decreased comparing with PA66. The reason is due to the agglomeration of PEPA in PA66.

Table 4. Mechanical properties of PA66 at different ratios of $\mathrm{MH}$ and PEPA

\begin{tabular}{llll}
\hline No. & $\begin{array}{l}\text { Tensile } \\
\text { strength } \\
(\mathrm{MPa})\end{array}$ & $\begin{array}{c}\text { Impact } \\
\text { strength } \\
\left(\mathrm{kJ} \cdot \mathrm{m}^{-2}\right)\end{array}$ & $\begin{array}{l}\text { Elongation at } \\
\text { break } \\
(\%)\end{array}$ \\
\hline 1 & 67.6 & 6.8 & 51.4 \\
2 & 65.9 & 5.6 & 23.3 \\
3 & 65.3 & 4.3 & 24.6 \\
4 & 64.8 & 4.1 & 21.7 \\
& & & \\
5 & 64.6 & 3.8 & 20.2 \\
& & & \\
6 & 64.1 & 3.5 & 19.5 \\
\hline
\end{tabular}




\section{Conclusion}

In the experiment, the effects of different conditions on the modification magnesium hydroxide were investigated, and the modification conditions of magnesium hydroxide with silane coupling 702 were obtained. The crystal structure of the modified magnesium hydroxide was not destroyed by XRD analysis of the modified magnesium hydroxide.

The influence of different conditions on the modification of magnesium hydroxide was investigated in the experiment, and the conditions of modifying magnesium hydroxide by silane coupling agent 702 were obtained. The XRD spectrum of the modified magnesium hydroxide show that the crystal structure of the modified magnesium hydroxide is not damaged.

The flame retardancy of PA66 was improved obviously and the mechanical properties of PA66 were less affected by adding the silane coupling 702 and PEPA. When $\mathrm{x}(\mathrm{MH})$ : X (PEPA): X $($ PA66) $=24(\mathrm{phr})$ : 7 (phr): 100 (phr), the vertical LOI of MH/PEPA/PA66 composite is $32.5 \%$, the direct combustion is $\mathrm{V}-0$. The change of tensile strength is small and the tensile strength changes little.

\section{Acknowledgments}

Thanks to the guidance program of Liaoning Provincial Department of Science and Technology (2019-ZD-0370).

Thanks to the Doctoral entrepreneurship and innovation program of Yingkou Institute of Technology.

\section{References}

1. Zhang H.X., Su G.X, Zhang N.(2018)Magnesium hydroxide surface modification and application in high density polyethylene.E.P.application,7:117121

2. Tang X.Q., Ren B., Li B.(2018)Effect of Magnesium Hydroxide Surface Modification on Properties of Flame Retardant PA6 Composites.Application of Engineering Plastics, 12: 42-47.

3. Gao Y, Wang H, Su Y.(2008) Influence of magnesium source on the crystallization behaviors of magnesium hydroxide.Journal of Crystal Growth, 16:3771-3778

4. Li Y.D., Sui M.(2000) preparation of $\mathrm{Mg}(\mathrm{OH})_{2}$ Nanorods..Adv. Mater, 12: 818-821

5. Wang Q.,LiC.H.,G M.(2014)Hydrothermal synthesis of hexagonal magnesium hydroxide nanoflakes. Material Research Bulletin51: 3539.

6. Wang S.L., Yang X.X., Wang F., Song Z.J.(2019) Effect of Modified Hydrotalcites on Flame Retardancy and Physical Properties of Paper .Bioresources. 14 :3991-4005.

7. Wang L, Li B, Hu Z.(2013) Effect of nickel on the properties of composites composed of layered double hydroxides and ethylene vinyl acetate copolymer. Applied Clay Science, 72:138-146.

8. Kalali E. N, Wang X., Wang D.Y. (2015) Functionalized layered double hydroxide-based epoxy nanocomposites with improved flame retardancy and mechanical properties[J]. Journal of Materials Chemistry A, 3 :6819-6826. 